Supporting Information for

\title{
The Inverted Region in Bimolecular Electron Transfer in Solution Enabled by Delocalization
}

By Norihiko Takeda and John R. Miller

\section{Experimental Details}

Tetrahydrofuran (THF) was distilled from sodium-benzophenone. Regioregular poly(3decylthiophene-2,5-diyl), P3DT, was purchased from Aldrich and used as received. Quaterthiophene, $T_{4}$, was from Aldrich and was purified by recrystallization from toluene followed by vacuum sublimation. Most quinones, acridine, fumaronitrile, TCNE and 1,4dicyanobenzene were from Aldrich or Fluka and were vacuum sublimed; 2,3dicyanobenzoquinone (95\%, Ambinter) was recrystallized. Fluoranthene, 9-fluorenone, 9methylanthracene, and benzophenone were zone refined. Ferrocene (recrystallized) was from Alfa and vacuum sublimed. Decamethylferrocene from Aldrich and was recrystallized from ethanol and vacuum sublimed._Tetrabutylammoniumtetrafluoroborate $\left(\mathrm{TBABF}_{4}\right)$ was from Fluka (electrochemical grade) was recrystallized from ethylacetate and dried overnight under vacuum at $80^{\circ} \mathrm{C}$.

Pulse Radiolysis was performed at the Laser-Electron Accelerator Facility (LEAF) at Brookhaven National Laboratory. ${ }^{1}$ Samples were prepared in air free conditions as described previously. ${ }^{2,3}$ Electrochemical measurements were performed with a BAS 100B electrochemical analyzer using a Pt disk (1.6mm dia.) as working electrode. A Pt wire and an $\mathrm{Ag} / \mathrm{Ag}^{+}\left(10 \mathrm{mM} \mathrm{AgNO}_{3}\right.$ in $0.1 \mathrm{M}$ $\mathrm{TBABF}_{4} /$ acetonitrile) were served as a counter and a reference electrode, respectively.

Supporting electrolyte was $0.1 \mathrm{M} \mathrm{TBABF}_{4}$ in THF and purged with argon prior to measurements. Ferrocenium/ferrocene $\left(\mathrm{Fc}^{+/ 0}\right)$ was used as internal reference. When $\mathrm{Fc}^{+/ 0}$ interfered with the analyte redox wave, decamethylferrocenium/decamethylferrocene $\left(\mathrm{dmFc}^{+/ 0}=-0.41 \mathrm{~V} \mathrm{vs} \mathrm{Fc}^{+/ 0}\right.$ in our measurements) was used instead.

Computations utilized Gaussian 09, Gaussian $16^{4}$ and Qchem $5 \cdot 0.2^{5}$ for $\mathrm{GMH}^{6,7}$ and FCD ${ }^{8}$ calculations. 
Electron donors (P3DT ${ }^{-\bullet}$ and $\mathrm{T}_{4}^{-\bullet}$ ) were created in THF by pulse-radiolysis. Pulses of $9 \mathrm{MeV}$ electrons from the LEAF accelerator created solvated electrons which rapidly attached to P3DT or $\mathrm{T}_{4}$ to create the anions. Both donor anions showed two absorption bands in vis-NIR region; $\sim 860 \mathrm{~nm}$ and $\sim 2400 \mathrm{~nm}$ for P3DT $^{\bullet}$ and $\sim 685 \mathrm{~nm}$ and $\sim 1320 \mathrm{~nm}$ for $\mathrm{T}_{4}{ }^{-}$. Bimolecular electron transfer rate constants were derived from the decay of transient absorption of $\mathrm{P}^{-1} \mathrm{TT}^{-\bullet}$ or $\mathrm{T}_{4}^{-{ }^{-}}$in the presence and absence of acceptors in solution. Growth of acceptor anions could sometimes be observed, but was often obscured by the neutral P3DT or $\mathrm{T}_{4}$ absorption. For moderately to highly exoergic reactions, donor absorption decayed to levels indistinguishable from zero as shown in Figure S1. For weakly exoergic reactions some donor absorption remains after decay due to ET to the acceptor. From such data equilibrium constants were derived according to eq S1.

For less exoergic reactions, some donor absorption remains after decay caused by the acceptor, as seen, for example, in Figure S3. Those remaining absorptions were used to deduce the equilibrium constants. In those cases the apparent decay rate contains contributions from both forward and back reactions. The forward rate constants are reported.

$$
\left.\mathrm{D}^{\bullet}+\mathrm{A} \rightleftharpoons \mathrm{D}+\mathrm{A}^{-\bullet}, \quad \mathrm{D}=\mathrm{P} 3 \mathrm{DT} \text { or } \mathrm{T}_{4} \quad \text { (eq. } \mathrm{S} 1\right)
$$

The slower decay of the donors when no acceptor is added is seen in Figures S1 and S2. These decays, due principally to reactions with positive ions, are included in the fits so that the obtained rate constants reflect only reactions with the acceptors. 


\section{Free Energy Changes from Equilibria}

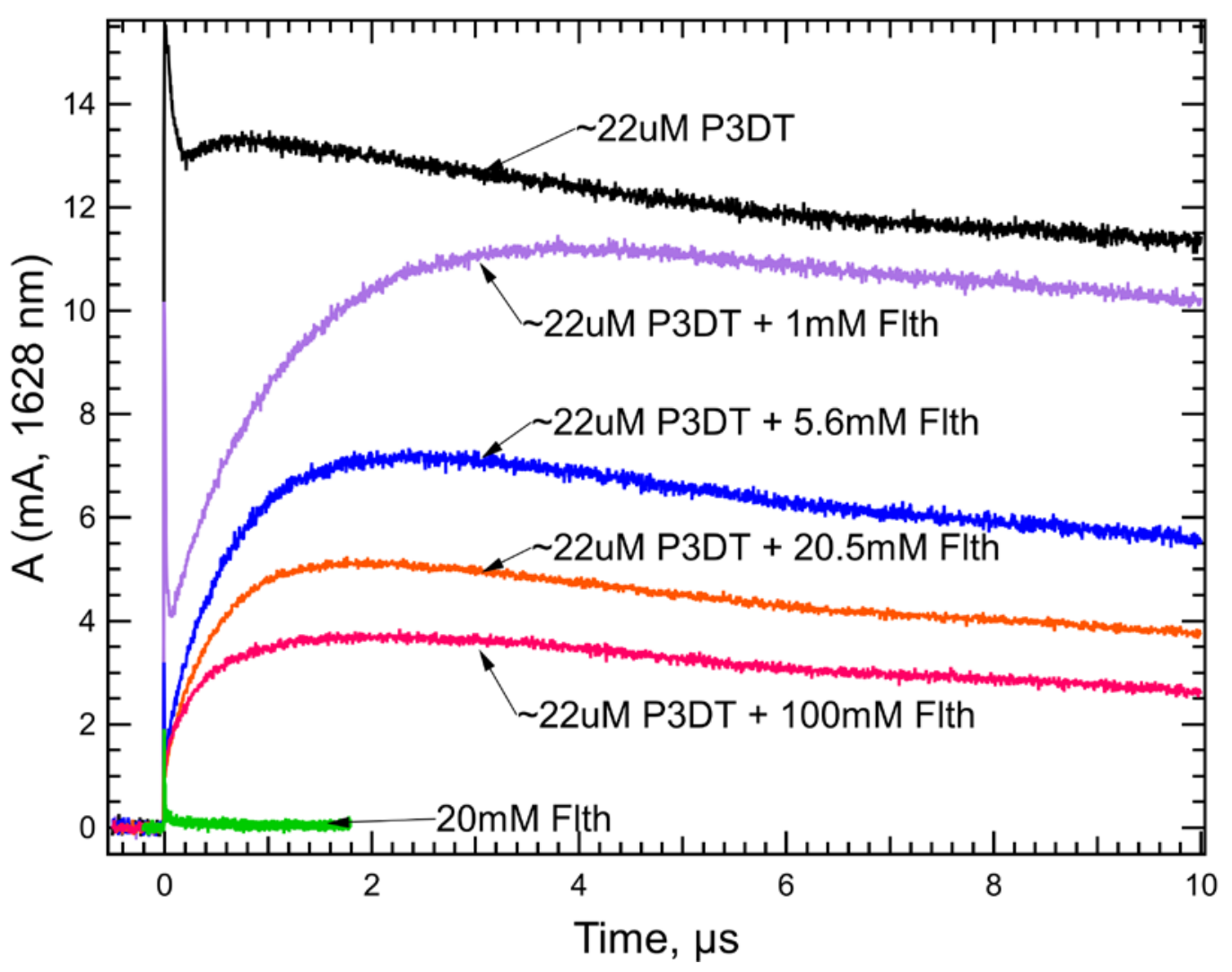

Figure S1. Transient absorption at $1628 \mathrm{~nm}$ after pulse radiolysis of $22 \mathrm{uM}$ P3DT molecules alone and with varied concentrations of fluoranthene (Flth) in THF. These data determine the equilibrium constant giving $\Delta \mathrm{G}^{\circ}=0.146 \mathrm{eV}$ reported in the second line of Table 1 for the reaction P3DT ${ }^{*-}+$ Flth $\rightleftharpoons$ P3DT + Flth $^{-}$ 


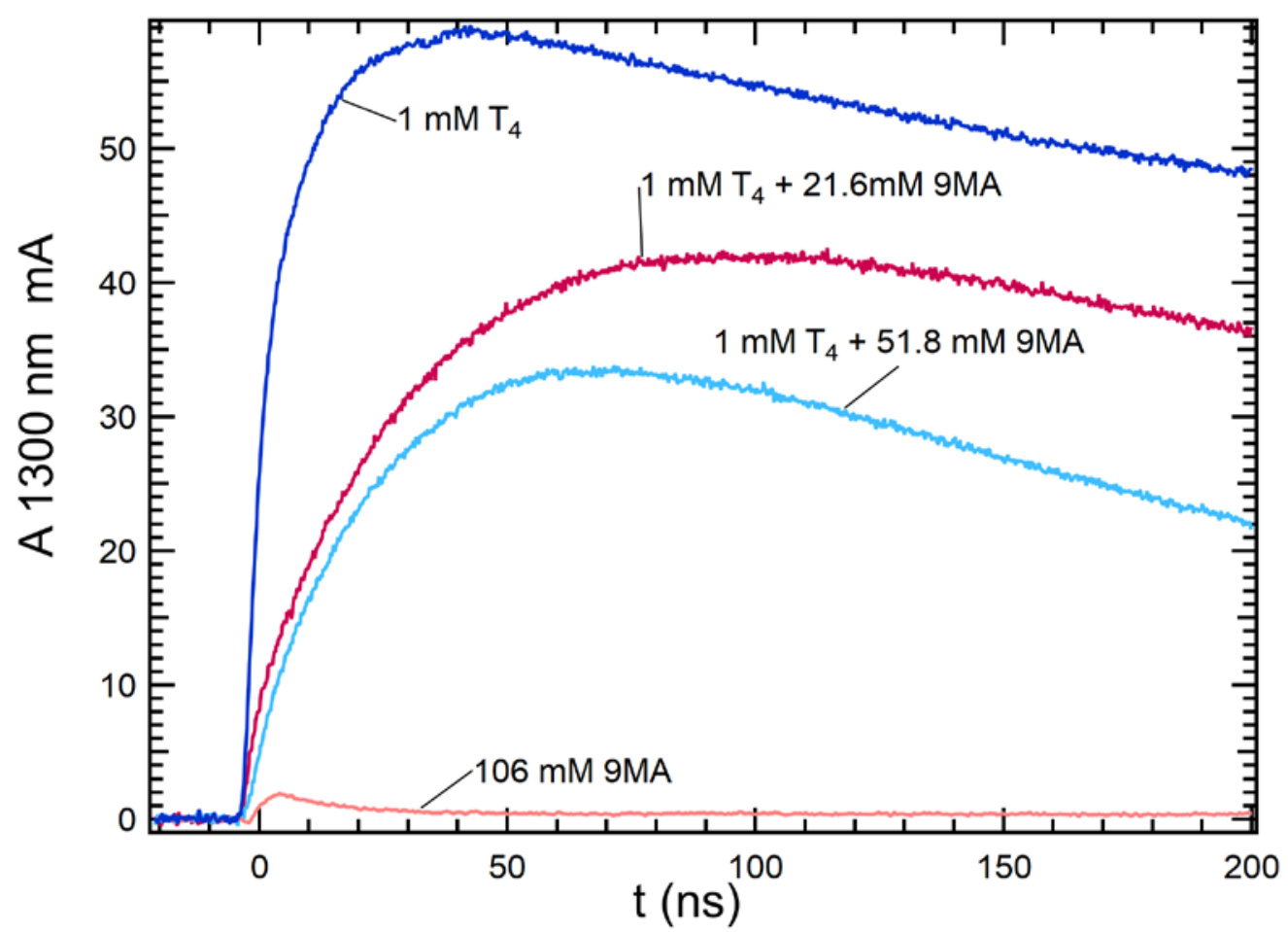

Figure S2. Transient absorption at $1300 \mathrm{~nm}$ for $1 \mathrm{mM} \mathrm{T} \mathrm{T}_{4}$ in $\mathrm{THF}$ alone and with two different concentrations of 9-methylanthracene (9MA). In the mixtures, due to its 20-50 times larger concentration, 9MA initially captures most electrons. Electron transfer to $\mathrm{T}_{4}$ yields $\mathrm{T}_{4}{ }^{-{ }^{-}}$rising to equilibrium values at $\sim 100 \mathrm{~ns}$. At longer times some decay occurs due to an $\sim 0.4 \%$ impurity in 9MA. 


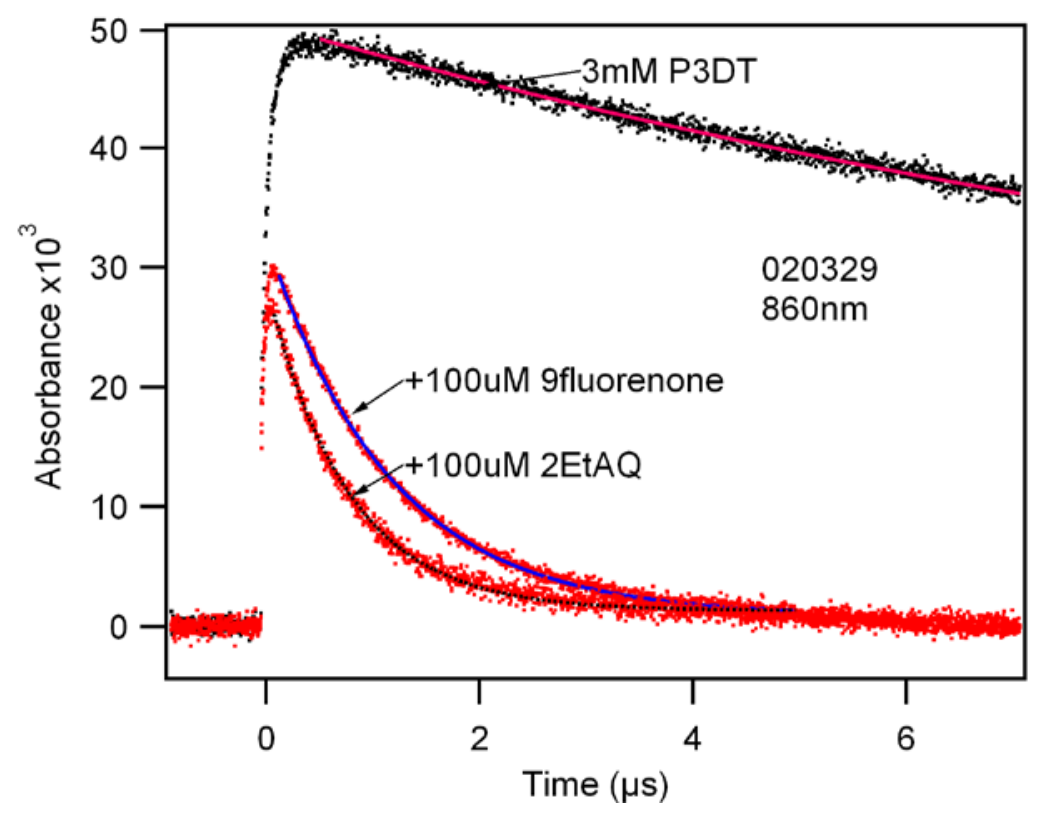

Figure S3. Transient absorption at the $860 \mathrm{~nm}$ of P3DT anion without and with added 9fluorenone and 2-ethylanthraquinone (2-EtAQ). 


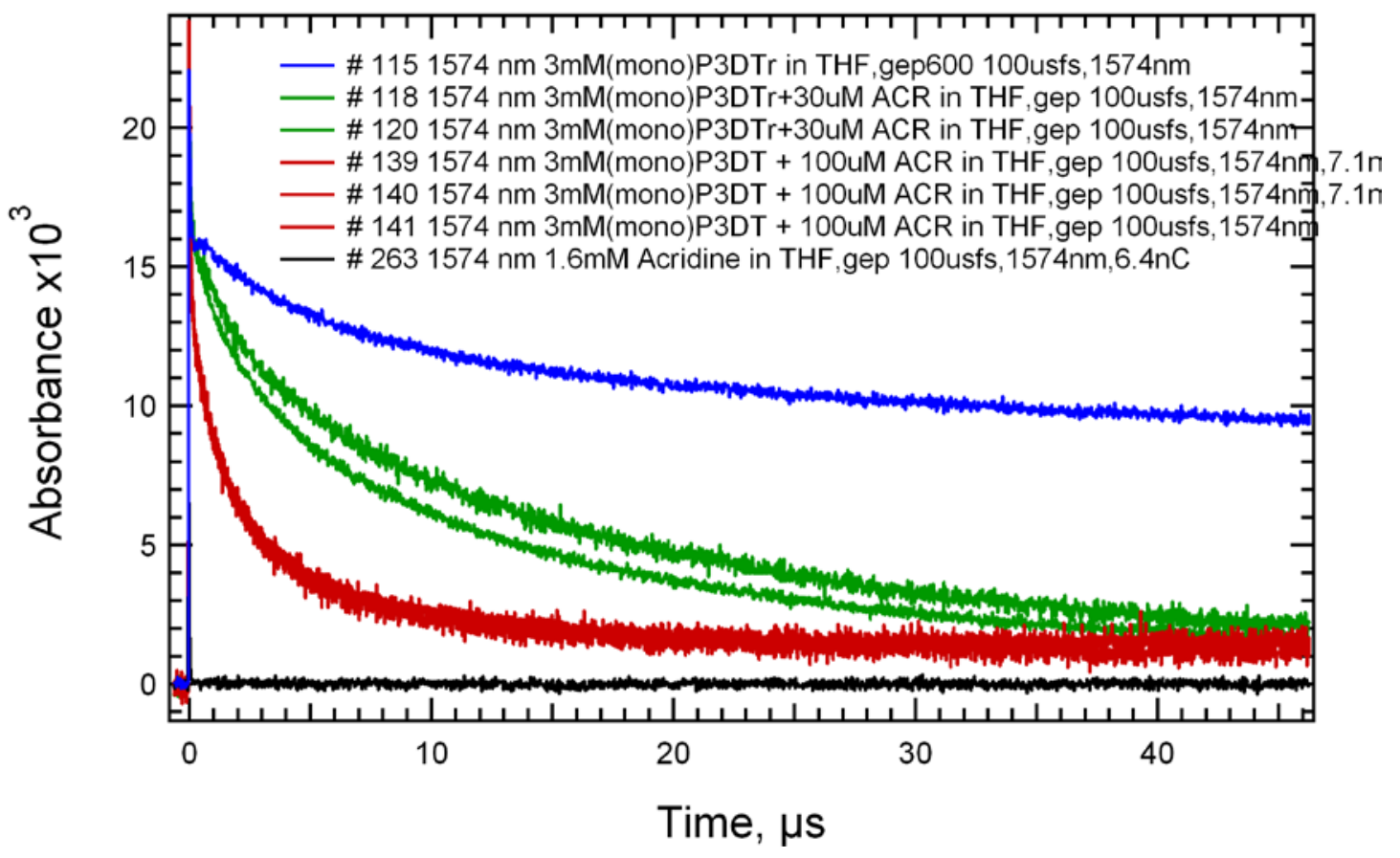

Figure S4. Transient absorption of P3DT anion at $1574 \mathrm{~nm}$ without and with acridine in THF. 


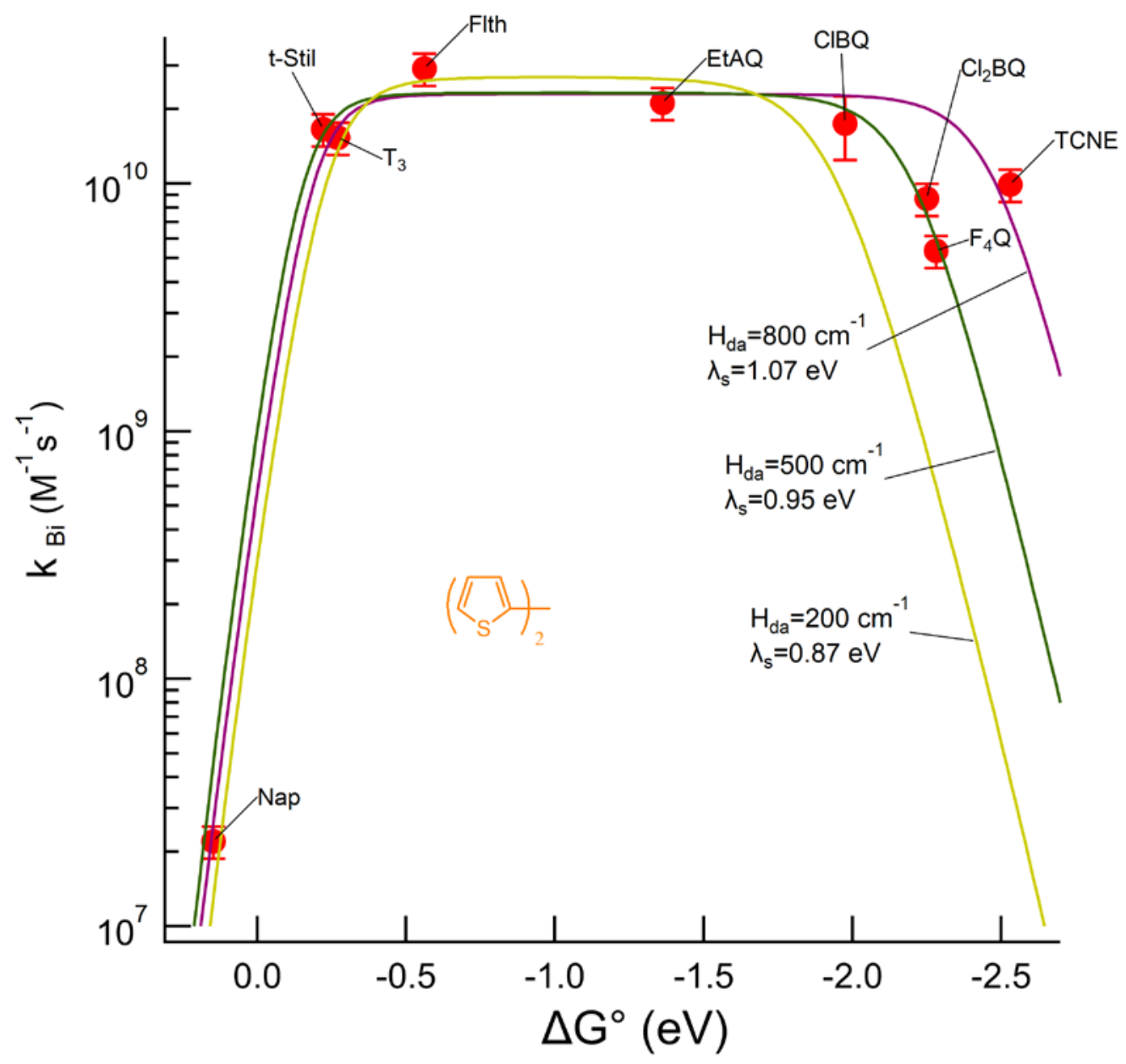

Figure S5. Rate constants for transfer of electrons from anions of bithiophene $\left(T_{2}\right)$ to several acceptors in THF; naphthalene (Nap), trans-stilbene (t-Stil), terthiophene $\left(\mathrm{T}_{3}\right)$, fluoranthene (Flth), 2-ethyl-1,4-anthraquinone (2-EtAQ), chloro-1,4-benzoquinone (ClQ), 2,5-dichloro-1,4benzoquinone $\left(2,5-\mathrm{Cl}_{2} \mathrm{BQ}\right)$, tetracyanoethylene (TCNE), and tetrafluoro-1,4-benzoquinone $\left(\mathrm{F}_{4} \mathrm{Q}\right)$. Decays of transient absorption of $\mathrm{T}_{2}^{-\bullet}$ were monitored at $480 \mathrm{~nm}$ to deduce the rates. Free energy changes, $\Delta G^{\circ}$, were determined from the equilibrium constant in THF without electrolyte for electron transfer from $\mathrm{T}_{2}{ }^{-\bullet}$ to naphthalene and electrochemical redox potentials for acceptors similar to the procedure described in Table 1 . The fits with eqs $1-2$ with $\mathrm{H}_{\mathrm{ab}}$ fixed to 200,500 or $800 \mathrm{~cm}^{-1}$ and $\lambda_{v}=0.144 \mathrm{eV}$ gave values of $\lambda_{s}$ shown in the figure. All had T=296 K, $\omega$ $=1500 \mathrm{~cm}^{-1}, \mathrm{k}_{\mathrm{d}}=2.5 \times 10^{10} \mathrm{M}^{-1} \mathrm{~s}^{-1}$ with the points for $2,5-\mathrm{Cl}_{2} \mathrm{BQ}, \mathrm{F}_{4} \mathrm{Q}$ and TCNE not included. This comparison suggests that a value of $\mathrm{H}_{\mathrm{ab}}$ near $200 \mathrm{~cm}^{-1}$ does not provide a good description and that $\mathrm{H}_{\mathrm{ab}} \sim 500 \mathrm{~cm}^{-1}$ is plausible, even appealing, but the data do not support a clear value of $\mathrm{H}_{\mathrm{ab}}$ because all the points possibly showing inverted behavior are affected to unknown extents by reactions forming excited products. 


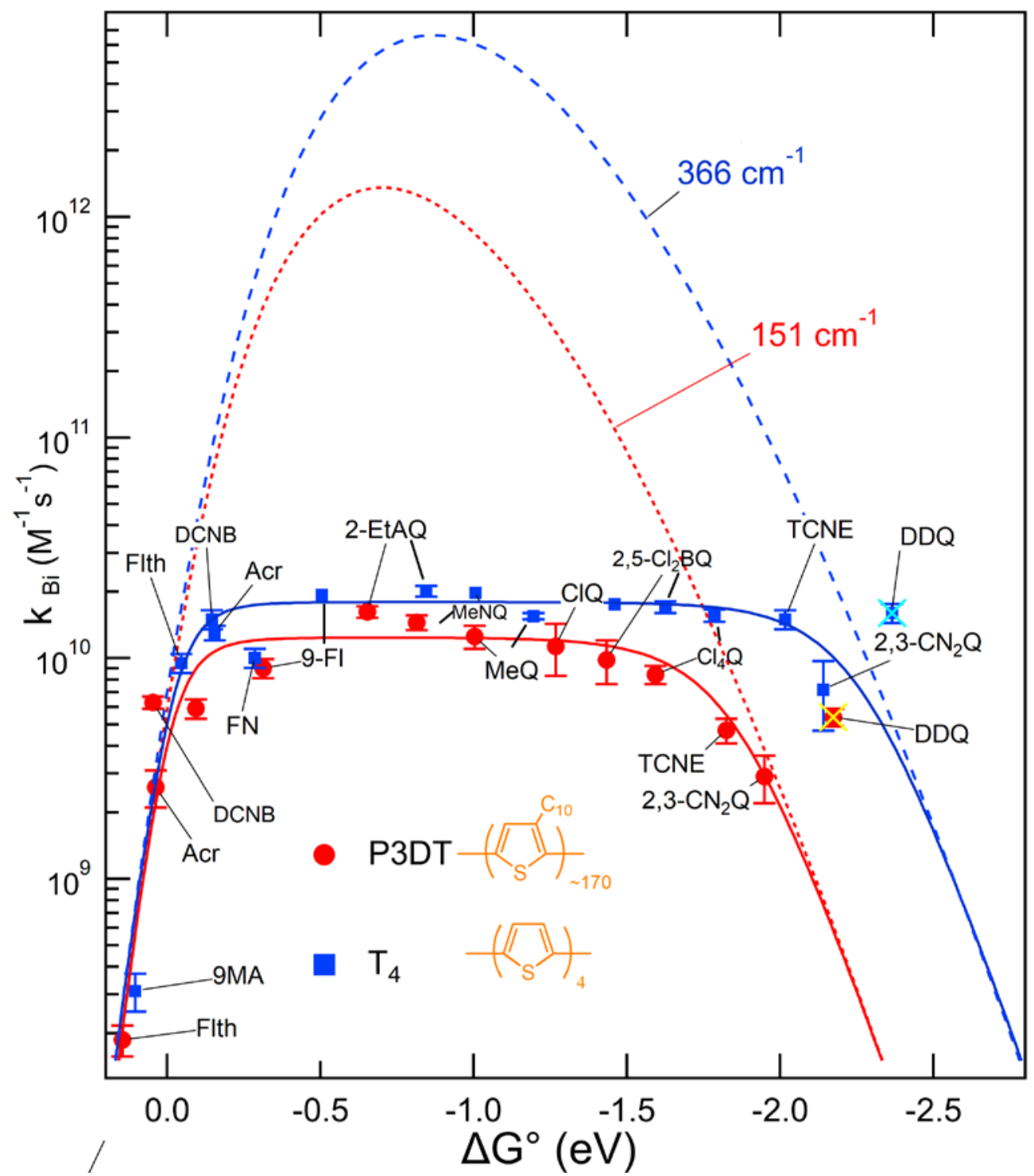

Figure S6. Predictions (dashed curves) by eqs 1-2 for bimolecular electron transfer rate constants from $\mathrm{T}_{4}^{-\bullet}$ or $\mathrm{P}^{-} \mathrm{DT}^{-\bullet}$ with the parameters of Figure 1 and Table 2, but with the diffusion limit removed, $\mathrm{k}_{\mathrm{d}}>>\mathrm{k}_{\mathrm{act}}$. Eq 1 is for nonadiabatic electron transfer and does not include adiabatic limits that can reduce the rates, especially near the peak. Here we do not include this limit, but note the complexities summarized recently by Rafiq and Scholes. ${ }^{9}$ Impacts of adiabaticity are more likely for the $\mathrm{T}_{4}$ (blue curve). The dashed curves thus represent electron transfer rate constants for $\mathrm{T}_{4}^{-\bullet}$ or $\mathrm{P} \mathrm{DT}^{-}$in contact with acceptors. For comparison data and fits of Figure 1 are seen at the bottom of the graph. 


\section{Computed reorganization energies}

Internal reorganization energies were computed with b3lyp/6-31+g(d) for conversion of $\mathrm{T}_{4}$ to $\mathrm{T}_{4}^{-\bullet}$ and $\mathrm{T}_{11}$ to $\mathrm{T}_{11}{ }^{-\bullet}$ using the four-point method ${ }^{10}$ obtaining the values in Table S1.

Table S1. Computed internal reorganization energies, $\lambda_{v}$, for conversion of $T_{11}, T_{4}, T_{2}$ and three acceptors to radical anions and solvation energies, $\Delta \mathrm{G}_{\mathrm{s}}^{\mathrm{o}}$, for the same compounds computed in THF by the SMD method. All used b3lyp/6-31+g(d).

\begin{tabular}{|l|l|l|l|l|l|l|}
\hline Molecule & $\mathrm{T}_{11}$ & $\mathrm{~T}_{4}$ & $\mathrm{~T}_{2}$ & $\mathrm{Cl}_{4} \mathrm{Q}$ & $2,3-\mathrm{CN}_{2} \mathrm{Q}$ & $\mathrm{TCNE}$ \\
\hline$\lambda_{\mathrm{V}}(\mathrm{eV})$ & 0.069 & 0.115 & 0.144 & 0.266 & 0.216 & 0.135 \\
\hline$\Delta \mathrm{G}_{\mathrm{s}}^{\mathrm{o}}(\mathrm{eV})$ & -0.72 & -1.22 & -1.59 & -1.34 & -1.19 & -1.23 \\
\hline
\end{tabular}

From the values in Table S1 we can see that the computed internal reorganization energies are larger for $T_{4}$ than for $T_{11}$ and still larger for the acceptors. Since $\lambda_{\mathrm{V}}$ for an ET reaction is the sum of contributions from both the donor and acceptor, the total for $\mathrm{T}_{4}$ plus the average for the three acceptors is $0.322 \mathrm{eV}$; the similar $\lambda_{v}$ for $\mathrm{T}_{11}$ reactions is $0.276 \mathrm{eV}$ so the ratio $\lambda_{\mathrm{v}}\left(\mathrm{T}_{4}\right) / \lambda_{\mathrm{v}}\left(\mathrm{T}_{11}\right)=1.17$.

In Marcus's equation for two spheres in a dielectric continuum, the solvent reorganization energy,

$$
\lambda_{\mathrm{s}}=(\Delta \mathrm{e})^{2}\left(\left(2 \mathrm{r}_{\mathrm{d}}\right)^{-1}+\left(2 \mathrm{r}_{\mathrm{a}}\right)^{-1}-\left(2 \mathrm{R}_{\mathrm{da}}\right)^{-1}\right)\left(\varepsilon_{\mathrm{op}}{ }^{-1}-\varepsilon_{\mathrm{s}}^{-1}\right) \quad \text { (eq. S2) }
$$

where $\Delta \mathrm{e}$ is the charge transferred, $\mathrm{r}_{\mathrm{d}}$ and $\mathrm{r}_{\mathrm{a}}$ are radii of spheres representing the donor and acceptor, $\mathrm{R}_{\mathrm{da}}$ is the donor-acceptor distance and $\varepsilon_{\mathrm{op}}$ and $\varepsilon_{\mathrm{s}}$ are the optical and static dielectric constants.

The form of the Born solvation energy

$$
\Delta \mathrm{G}_{\mathrm{s}}^{\mathrm{o}}=-\mathrm{z} / \mathrm{r}_{\mathrm{d}}\left(1-\varepsilon_{\mathrm{s}}{ }^{-1}\right)
$$

where $\mathrm{z}$ is a constant is similar to eq S2. For the model of two touching spheres $\left(\mathrm{R}_{\mathrm{da}}=2 \mathrm{r}_{\mathrm{d}}\right)$ the dependence of $\lambda_{s}$ on $r_{d}$ is the same as that in eq S3 as seen in Figure S7 which compares $\lambda_{s}$ with $\Delta \mathrm{G}_{\mathrm{s}}^{\mathrm{s}}$ as functions of $\mathrm{r}_{\mathrm{d}}$. 


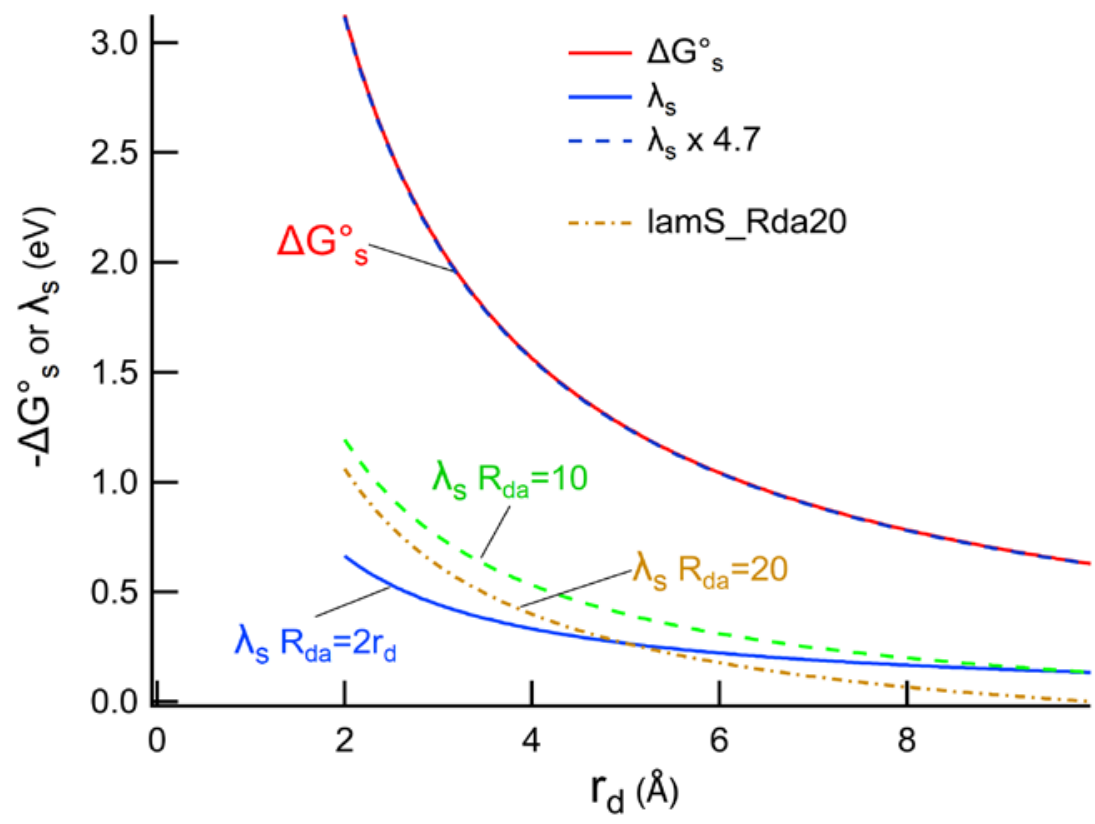

Figure S7. Comparison of $-\Delta \mathrm{G}_{\mathrm{s}}^{\mathrm{o}}$ (eq S3) with $\lambda_{\mathrm{s}}$ (eq S2) vs. $\mathrm{r}_{\mathrm{d}}$ with $\mathrm{r}_{\mathrm{a}}=\mathrm{r}_{\mathrm{d}}$ and $\mathrm{R}_{\mathrm{da}}=2 \mathrm{r}_{\mathrm{d}}(-)$ Here $\varepsilon_{\mathrm{op}}=2.0$ and $\varepsilon_{\mathrm{s}}=7.6$.

In figure $\mathrm{S} 7 \lambda_{\mathrm{s}}$ from, eq $\mathrm{S} 2$ and $-\Delta \mathrm{G}_{\mathrm{s}}^{\mathrm{o}}$ from eq $\mathrm{S} 3$ depend similarly on the size, $\mathrm{r}_{\mathrm{d}}$, of the donor and acceptor molecules. $\lambda_{s}$ scaled by a factor of $4.7(----)$ matches $-\Delta \mathrm{G}^{\circ}{ }_{s}$ for touching spheres $\left(R_{d a}=2 r_{d}\right)$. The two curves fall on top of each other. This scaling lets us estimate the ratio $\lambda_{s}\left(T_{4}\right) /$ $\lambda_{s}\left(T_{11}\right)$ from the ratio of computed solvation energies, $\lambda_{s}\left(T_{4}\right) / \lambda_{s}\left(T_{11}\right)=\Delta G_{s}^{o}\left(T_{4}\right) / \Delta G_{s}^{o}\left(T_{11}\right)$. We do note that the less relevant comparison for $R_{d a}$ fixed as $r_{d}$ changes is less similar, though perhaps adequate (Curves for $R_{d a}=10$ and $20 \AA$ shown as examples in Figure S7). As with $\lambda_{v}, \lambda_{s}$ is the sum of contributions from the donor and acceptor, so together with the average solvation energy $\Delta \mathrm{G}_{\mathrm{s}}^{\mathrm{o}}=-1.25 \mathrm{eV}$ for the three acceptors in Table $\mathrm{S} 1$ the computations arrive at $\lambda_{\mathrm{s}}\left(\mathrm{T}_{4}+\mathrm{A}\right) /$ $\lambda_{s}\left(T_{11}+A\right)=1.25$. Here $\lambda_{s}\left(T_{4}+A\right)$ refers to the total reorganization energy for $T_{4}$ and acceptors, using the average of the three acceptors in Table S1. The fits in Figure 1 constrain the reorganization energies to have this ratio and the similar ratio described above for $\lambda_{\mathrm{v}}$. A global fit with ratios that are twice as large, $\lambda_{\mathrm{S}}\left(\mathrm{T}_{4}\right) / \lambda_{\mathrm{s}}\left(\mathrm{T}_{11}\right)=1.34$ and $\lambda_{\mathrm{v}}\left(\mathrm{T}_{4}\right) / \lambda_{\mathrm{v}}\left(\mathrm{T}_{11}\right)=1.50$ gave a similar $\mathrm{H}_{\mathrm{ab}}(\mathrm{P} 3 \mathrm{DT})=85 \mathrm{~cm}^{-1}$ and $\mathrm{H}_{\mathrm{ab}}\left(\mathrm{T}_{4}\right)=168 \mathrm{~cm}^{-1}$, although with these constraints the solvent reorganization energies are unreasonably small, $\lambda_{s}\left(T_{11}\right)=0.20$ and $\lambda_{s}\left(T_{4}\right)=0.29 \mathrm{eV}$. If we require 
$\lambda_{s}\left(T_{4}\right) / \lambda_{s}\left(T_{11}\right)=1.0$ we obtain $H_{a b}=52$ and $304 \mathrm{~cm}^{-1}$. We conclude that $\mathrm{H}_{\mathrm{ab}}(\mathrm{P} 3 \mathrm{DT})$ is smaller than $\mathrm{H}_{\mathrm{ab}}\left(\mathrm{T}_{4}\right)$ and that fits based on the computed constraints are most sensible. 


\section{Computing Electronic Couplings by Extension to Symmetry}

Electronic couplings, $\mathrm{H}_{\mathrm{ab}}$, are readily computed for pairs in which the donor and acceptor are identical and arranged symmetrically. For example DFT computations on $\mathrm{T}_{1}, \mathrm{~T}_{1}$ or $\mathrm{T}_{11}, \mathrm{~T}_{11}$ with $\mathrm{C}_{2 \mathrm{v}}$ symmetry produce symmetric and antisymmetric KS orbitals different in energy by $2 H_{d a}$. Getting $H_{d a}$ is more difficult for $\mathrm{T}_{11}, \mathrm{~T}_{1}$, but we may obtain $H_{d a}\left(\mathrm{~T}_{11}, \mathrm{~T}_{1}\right)$ by extending the structure to the symmetric one $\mathrm{T}_{11}, \mathrm{~T}_{1}, \mathrm{~T}_{11}$ shown in Figure $\mathrm{S} 8$.

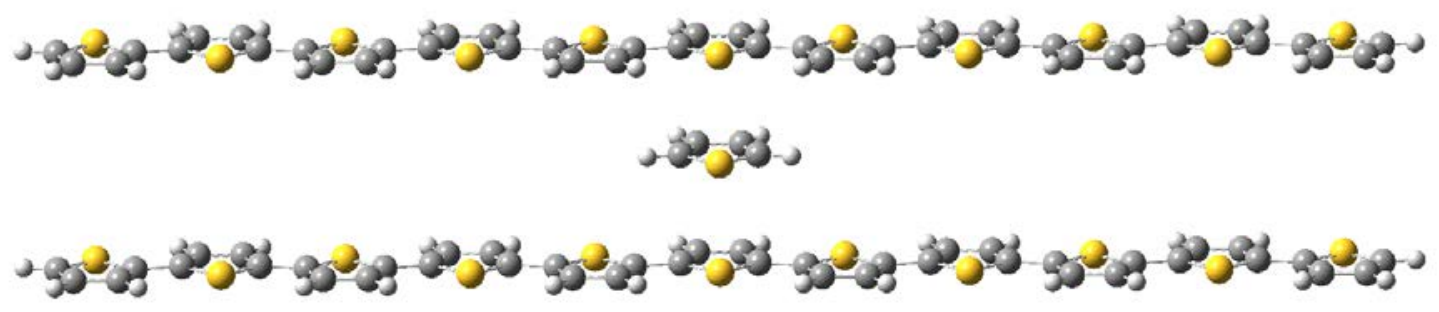

Figure S8. A $\quad$ A $\mathrm{C}_{2 \mathrm{v}}$ symmetric structure, $\mathrm{T}_{11}, \mathrm{~T}_{1}, \mathrm{~T}_{11}$, comprised of two of two 11-unit and one one-unit thiophene oligomers.

From results of computations on $\mathrm{T}_{11}, \mathrm{~T}_{1}, \mathrm{~T}_{11} H_{d a}\left(\mathrm{~T}_{11}, \mathrm{~T}_{1}\right)$ may be obtained by the superexchange relation $\mathrm{H}_{\mathrm{ac}}=\mathrm{H}_{\mathrm{ab}} \mathrm{H}_{\mathrm{bc}} / \Delta \mathrm{E}_{\mathrm{ab}}$. Here $\mathrm{H}_{\mathrm{ab}}=\mathrm{H}_{\mathrm{bc}}$ is the desired $H_{d a}\left(\mathrm{~T}_{11}, \mathrm{~T}_{1}\right)$ and $\mathrm{H}_{\mathrm{ac}}$ is directly obtained as a difference between symmetric and antisymmetric KS orbitals from the computation, or more accurately from the solution to the three-state model. ${ }^{11}$

\section{CT Complexes?}

Could the electronic couplings $\mathrm{H}_{\mathrm{ab}}=151$ and $366 \mathrm{~cm}^{-1}$ (Table 2) give rise to complexes that would cause anions of P3DT or $\mathrm{T}_{4}$ to linger near the acceptors making the bimolecular rate constants appear larger? Figure S9 shows potential curves for a much larger coupling, $H_{a b}=1000$ $\mathrm{cm}^{-1}$, that predict only a small binding of $0.0307 \mathrm{eV}$ for a CT complex (upper panel). Binding would be much less for the smaller electronic couplings of 151 and $366 \mathrm{~cm}^{-1}$, and still smaller when the difference, $\Delta \mathrm{G}_{\mathrm{d}}{ }_{\text {}}$, of the donor and acceptor energies is not zero (lower panel). 

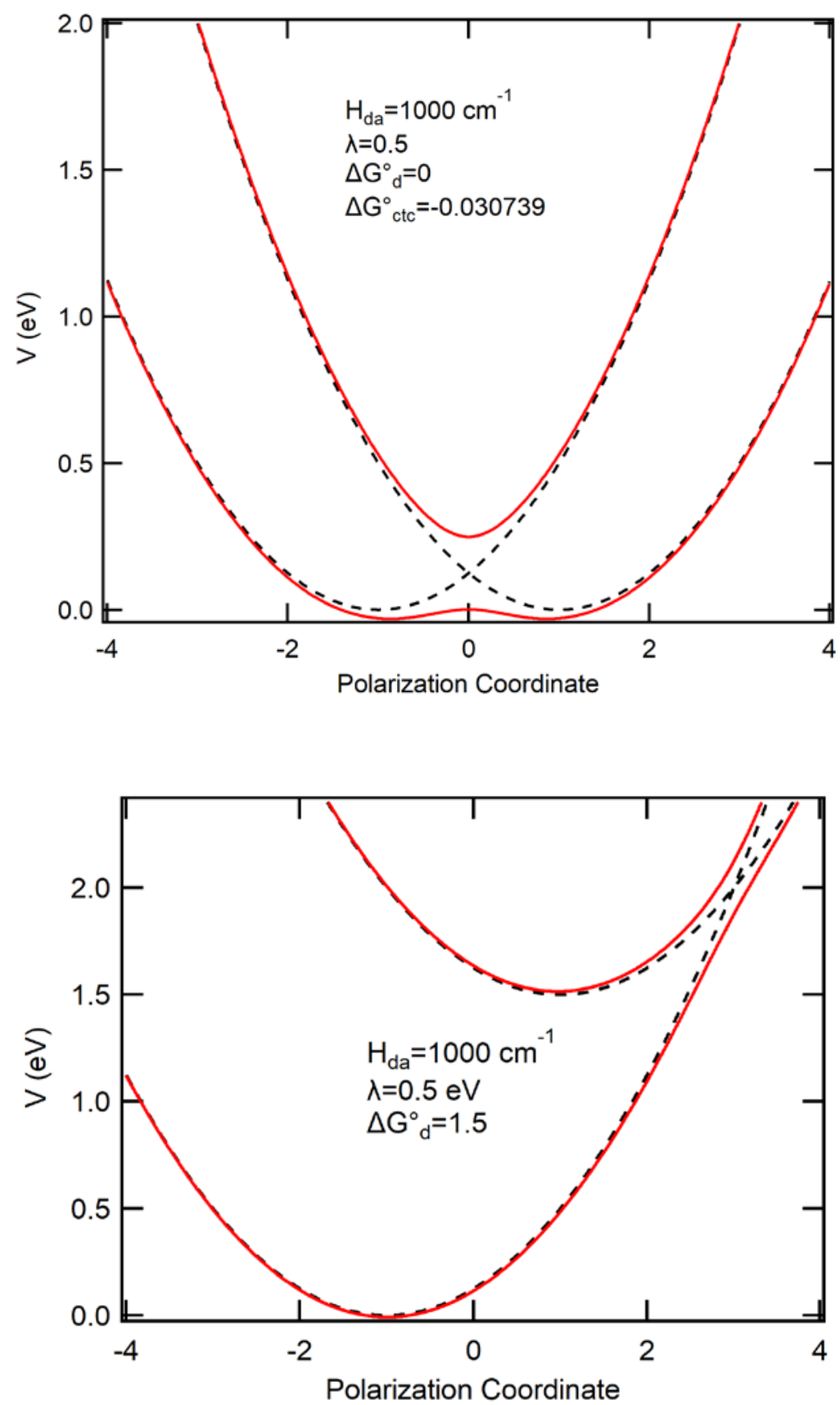

Figure S9. For $\Delta \mathrm{G}^{\circ}=0$ (upper) and $\Delta \mathrm{G}^{\circ}=-1.5 \mathrm{eV}$ (lower), both with $\mathrm{H}_{\mathrm{ab}}=1000 \mathrm{~cm}^{-1}$ and $\lambda=$ $0.5 \mathrm{eV}$. The curves predict a small, binding, $31 \mathrm{meV}$, for a reaction with $\Delta \mathrm{G}^{\circ}=0$ and none for the highly-exoergic, $\Delta \mathrm{G}^{\circ}=-1.5 \mathrm{eV}$. These predict negligible complexing. With the smaller values of $\mathrm{H}_{\mathrm{ab}}$ determined in Table 1, complexing would be even less likely. The potential curves were constructed for classical ET; $\lambda_{\mathrm{s}}=0.5 \mathrm{eV}$ and $\lambda_{\mathrm{v}}=0$. Inclusion of high frequency modes would make complexing even less likely. 


\section{Charge Recombination Reactions}

Figure S10 below is based on observations of Gould and coworkers. ${ }^{12-14}$ They found that the contact radical ion pair (CRIP) is bound, separating with $k_{\text {esc }}$ to free ions in $\sim 3$ ns in solvents like dichloroethane and acetonitrile. For times less than $\left(\mathrm{k}_{\mathrm{esc}}\right)^{-1}$ recombination with rate $\mathrm{k}_{\mathrm{CR}}$ to neutral ground state molecules occurs from this bound CRIP without the requirement that the ions diffuse together, given methods that prepare CRIPs very rapidly. These methods include photoexcitation either of charge-transfer complexes or with high concentrations of one of the partners. ${ }^{12,15-22}$ Charge recombination rate constants, $\mathrm{k}_{\mathrm{CR}}$, can then be measured without the need for the two ions to diffuse together. Charge recombination by the bound ion-pairs, CRIPs or SSIPs, thus becomes a pseudo-intramolecular enabling observation ${ }^{12,15-22}$ of the inverted region.

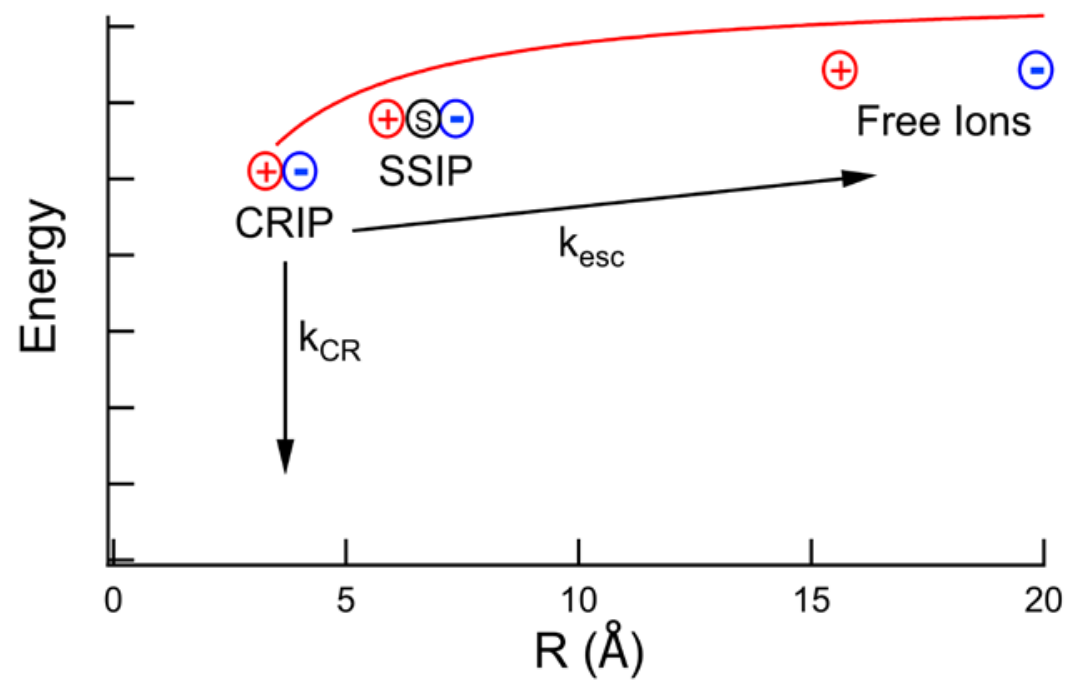

Figure S10. A schematic energy diagram including the contact radical ion pair (CRIP), the solvent-separated ion pair (SSIP) and free ions. 


\section{Relevance to Polymer Films in Organic Photovoltaic Cells}

Recent development of organic photovoltaic cells utilize donors and acceptors blended to form so-called bulk heterojunctions for efficient charge carrier generation. In these devices, excitons generated in donor and acceptor are transported to donor-acceptor interfaces, and subsequent charge transfer creates bound radical ion pairs. Charge dissociation forms free charge carriers, and electrons and holes are transported to opposite direction to generate photocurrent competing with recombination reactions. Driving force dependence of charge separation yield has been examined in blended films of polythiophene and polyfluorence based polymers as donor and fullerene based molecules, e.g. PCBM, as acceptor. ${ }^{23-}$ 26 In blended films both geminate recombination of contact radical ion pairs as well as bimolecular recombination of free polaron pairs could be influenced by energetics and electronic coupling of charged species. Bimolecular recombination has been shown to be an important loss mechanisms limiting the efficiency of organic photovoltaic cells. The device efficiency could be boosted if the driving force for the charge separation reaction $\left(D^{*}+A \rightarrow D^{+}+A^{-}\right.$or $D+A^{*} \rightarrow$ $\mathrm{D}^{+}+\mathrm{A}^{-}$) is in the normal region giving relatively fast rates whereas relatively small electronic couplings of delocalized charges in donor and acceptor (e.g. polymer and fullerene) pairs situate the charge recombination reaction $\mathrm{D}^{+}+\mathrm{A}^{-} \rightarrow \mathrm{D}+\mathrm{A}$ in the Marcus inverted region to make it relatively slower. The driving force for charge separation, $-\Delta G_{\mathrm{cs}}$ can be approximated by the difference between the exciton energy of donor or acceptor $\left(E_{\text {exciton }}\right)$ and the energy of the polaron pair ( $\mathrm{IP}_{\mathrm{donor}}-\mathrm{EA}_{\text {acceptor }}$ ) ignoring the Coulombic binding energy of polaron pairs. ${ }^{23-26}$ On the other hand, the energy change for the recombination reaction to the ground state can be approximated by the energy of the polaron pair ( $\left.\mathrm{IP}_{\text {donor }}-\mathrm{EA}_{\text {acceptor }}\right)$. 


\section{References}

1. Wishart, J. F.; Cook, A. R.; Miller, J. R. "The Leaf Picosecond Pulse Radiolysis Facility at Brookhaven National Laboratory", Rev. Sci. Instrum., 2004, 75, 4359-4366 10.1063/1.1807004.

2. Takeda, N.; Asaoka, S.; Miller, J. R. "Nature and energies of electrons and holes in a conjugated polymer, polyfluorene", J. Am. Chem. Soc., 2006, 128, 16073-16082 10.1021/ja062596h.

3. Asaoka, S.; Takeda, N.; Lyoda, T.; Cook, A. R.; Miller, J. R. "Electron and hole transport to trap groups at the ends of conjugated polyfluorenes", J. Am. Chem. Soc., 2008, 130, 11912-11920 10.1021/ja800426z.

4. Frisch, M. J.et al.,"Gaussian 16", 2016, Wallingford CT.

5. Shao, Y.et al.,"Q-Chem 5.0", 2017, Pleasanton, CA.

6. Cave, R. J.; Newton, M. D. "Calculation of Electronic Coupling Matrix Elements for Ground and Excited State Electron Transfer Reactions: Comparison of the Generalized Mulliken-Hush and Block Diagonalization Methods", J. Chem. Phys., 1997, 106, 92139226

7. Cave, R. J.; Newton, M. D. "Generalization of the Mulliken-Hush Treatment for the Calculation of Electron Transfer Matrix Elements", Chem. Phys. Lett., 1996, 249, 15-19 8. Voityuk, A. A.; Rosch, N. "Fragment Charge Difference Method for Estimating DonorAcceptor Electronic Coupling: Application to DNA Pi-Stacks", J. Chem. Phys., 2002, 117, 5607-5616 10.1063/1.1502255.

9. Rafiq, S.; Scholes, G. D. "From Fundamental Theories to Quantum Coherences in Electron Transfer", J. Am. Chem. Soc., 2019, 141, 708-722 10.1021/jacs.8b09059.

10. Nelsen, S. F.; Blackstock, S. C.; Kim, Y. "Estimation of Inner Shell Marcus Terms for Amino Nitrogen-Compounds by Molecular-Orbital Calculations", J. Am. Chem. Soc., 1987, 109, 677-682

11. Brunschwig, B. S.; Creutz, C.; Sutin, N. "Optical Transitions of Symmetrical MixedValence Systems in the Class II-lii Transition Regime", Chem. Soc. Rev., 2002, 31, 168184 Doi 10.1039/B008034i.

12. Gould, I. R.; Young, R. H.; Moody, R. E.; Farid, S. "Contact and Solvent-Separated Geminate Radical Ion-Pairs in Electron-Transfer Photochemistry", J. Phys. Chem., 1991, 95, 2068-2080 10.1021/j100158a031.

13. Arnold, B. R.; Farid, S.; Goodman, J. L.; Gould, I. R. "Absolute Energies of Interconverting Contact and Solvent-Separated Radical-Ion Pairs", J. Am. Chem. Soc., 1996, 118, 5482-5483 10.1021/ja9604020.

14. Arnold, B. R.; Noukakis, D.; Farid, S.; Goodman, J. L.; Gould, I. R. "Dynamics of Interconversion of Contact and Solvent-Separated Radical-Ion Pairs", J. Am. Chem. Soc., 1995, 117, 4399-4400 10.1021/ja00120a023.

15. Mataga, N.; Chosrowjan, H.; Shibata, Y.; Yoshida, N.; Osuka, A.; Kikuzawa, T.; Okada, T. "First Unequivocal Observation of the Whole Bell-Shaped Energy Gap Law in Intramolecular Charge Separation from S-2 Excited State of Directly Linked PorphyrinImide Dyads and Its Solvent-Polarity Dependencies", J. Am. Chem. Soc., 2001, 123, 12422-12423 10.1021/ja010865s.

16. Mataga, N.; Chosrowjan, H.; Taniguchi, S. "Ultrafast Charge Transfer in Excited Electronic States and Investigations into Fundamental Problems of Exciplex Chemistry: 
Our Early Studies and Recent Developments", J. Photochem.Photobiol. C-Photochem. Rev., 2005, 6, 37-79 10.1016/j.jphotochemrev.2005.02.003.

17. Asahi, T.; Mataga, N. "Charge Recombination Process of Ion-Pair State Produced by Excitation of Charge-Transfer Complex in Acetonitrile Solution - Essentially Different Character of Its Energy-Gap Dependence from That of Geminate Ion-Pair Formed by Encounter between Fluorescer and Quencher", J. Phys. Chem., 1989, 93, 6575-6578 10.1021/j100355a001.

18. Gould, I. R.; Farid, S. "Dynamics of Bimolecular Photoinduced Electron-Transfer Reactions", Acc. Chem. Res., 1996, 29, 522-528 10.1021/ar950053z.

19. Gould, I. R.; Ege, D.; Mattes, S. L.; Farid, S. "Return Electron-Transfer within Geminate Radical Ion-Pairs - Observation of the Marcus Inverted Region", J. Am. Chem. Soc., 1987, 109, 3794-3796 10.1021/ja00246a055.

20. Gould, I. R.; Moser, J. E.; Armitage, B.; Farid, S.; Goodman, J. L.; Herman, M. S. "Electron-Transfer Reactions in the Marcus Inverted Region. Charge Recombination Versus Charge Shift Reactions.", J. Am. Chem. Soc., 1989, 111, 1917-9

21. Vauthey, E. "Investigations of Bimolecular Photoinduced Electron Transfer Reactions in Polar Solvents Using Ultrafast Spectroscopy", J. Photochem. Photobiol. A, 2006, 179, 1-12 10.1016/j.jphotochem.2005.12.019.

22. Vauthey, E. "Direct Measurements of the Charge-Recombination Dynamics of Geminate Ion Pairs Formed Upon Electron-Transfer Quenching at High Donor Concentration", J. Phys. Chem. A, 2001, 105, 340-348 10.1021/jp0023260.

23. Ohkita, H.; Cook, S.; Astuti, Y.; Duffy, W.; Tierney, S.; Zhang, W.; Heeney, M.; McCulloch, I.; Nelson, J.; Bradley, D. D. C.; Durrant, J. R. "Charge Carrier Formation in Polythiophene/Fullerene Blend Films Studied by Transient Absorption Spectroscopy", J. Am. Chem. Soc., 2008, 130, 3030-3042 10.1021/ja076568q.

24. Coffey, D. C.; Larson, B. W.; Hains, A. W.; Whitaker, J. B.; Kopidakis, N.; Boltalina, O. V.; Strauss, S. H.; Rumbles, G. "An Optimal Driving Force for Converting Excitons into Free Carriers in Excitonic Solar Cells", J. Phys. Chem. C, 2012, 116, 8916-8923 10.1021/jp302275z.

25. Shuttle, C. G.; O'Regan, B.; Ballantyne, A. M.; Nelson, J.; Bradley, D. D. C.;

Durrant, J. R. "Bimolecular recombination losses in polythiophene: Fullerene solar cells", Phys. Rev. B, 2008, 78, 113201 10.1103/PhysRevB.78.113201.

26. Clarke, T. M.; Jamieson, F. C.; Durrant, J. R. "Transient Absorption Studies of Bimolecular Recombination Dynamics in Polythiophene/Fullerene Blend Films", J. Phys. Chem. C, 2009, 113, 20934-20941 10.1021/jp909442s. 